\title{
On the Energy Theory of Value: Economy and Policies
}

\author{
Peter Stallinga \\ University of The Algarve, Faro, Portugal \\ Email: peter.stallinga@gmail.com
}

How to cite this paper: Stallinga, $P$. (2020). On the Energy Theory of Value: Economy and Policies. Modern Economy, 11, 1083-1120.

https://doi.org/10.4236/me.2020.115081

Received: April 12, 2020

Accepted: May 25, 2020

Published: May 28, 2020

Copyright $\odot 2020$ by author(s) and Scientific Research Publishing Inc. This work is licensed under the Creative Commons Attribution International License (CC BY 4.0).

http://creativecommons.org/licenses/by/4.0/

\begin{abstract}
The Energy Theory of Value is presented on basis of clearly defined physical principles of energy and entropy. It is put in three postulates: economy is energy consumption, the universe (and thus economy) needs to increase its entropy, and in a free market every trade leaves people happier (defined in physical objectives). For the energy equivalence, we find a current energy value of $170 \mathrm{~mW}$ economy per (2019) US\$/year. Three basic questions are asked and answered: Is unfettered capitalism possible? Can we manage a steady-state economy in a free market? Do the energy transition policies make sense? It is found that if energy consumption is reduced, it will push many people into abject poverty.
\end{abstract}

\section{Keywords}

Labor Theory of Value (LTV), Physics, Politics, Energy Theory of Value (ETV)

\section{Introduction}

In this work, we are going to analyze the economy from a point of view of Physics. But first, a word on the relevancy of this work. That means mostly politics and we will use the introduction part for describing the current political situation and why what follows is relevant for today's society. The climate change subject is ideal to explain the ideas of this work.

Without a doubt the climate change is the most polemic topic in society. It seems that society is polarized in those that believe in the scenario that human-originated carbon dioxide $\left(\mathrm{CO}_{2}\right)$ causes significant and dramatic changes of our planet-so-called "Alarmists"-and those that are doubting these theories can stand up to scrutiny-so-called "Skeptics". (Note: the former often call the 
latter "Deniers" using the political tool of name calling, \#5 on the list of Rules of Disinformation (Citizen, 2019), trying to put climate skepticism on par with Holocaust denying, the gravest of immoral stances a person can take in modern society). The author belongs to the latter group, a scientist, and "science" and "skepticism" are as close to being synonyms as synonyms can get. Whatever theory is out there, a scientist will try to prove it incorrect. Without going into full detail (what we have done elsewhere (Stallinga \& Khmelinskii, 2014)), science, according to the Scientific Method of Popper, consists of 1) data processing to 2) come up with a hypothesis, 3) try to falsify (sic) the hypothesis and not trying to prove it, 4) falsify all alternative explanations for data of step 1, 5) present the case (with all pros and cons, and all the data and reasoning) to peers who can then try step 3 themselves making the entire research system scientific.

The Scientific Method was not used for this research topic. And the first observation we can thus make is that any claim of a "consensus in science" is false: since science was not done; there is no science and any consensus is thus virtual. In any case, as you have noted from the itemization above, voting is not part of the Scientific Method, and thus the entire concept of a consensus is ludicrous from the point of view of science. Voting belongs to the realm of politics. The self-acclaimed climate authority, IPCC (Intergovernmental Panel on Climate Change) is a political entity (formed by the United Nations and World Meteorological Organization), that starts with a conclusion and then works its way back to the relevant publications in literature to substantiate the claims in the reports. Now, alarm bells should ring when we see that the United Nations drums up a report about an issue with which they then increase their own influence in the world. It is a classic feedback mechanism and we have to be vigilant. It is reminding of a scheme used by your regular washing powder company that comes up with some (baloney) scientific research that proved that their washing powder cleans your clothes the best. It is rather naive to believe it face value, without further scrutiny.

This brings us to the pertinent question: who came up with the idea of climate change? That is, who came up with climate change as a political issue or instrument? That because the idea of a greenhouse effect was existing a lot longer than the identification of the problem. For instance Callendar (Callendar, 1938) or Ångström (Ångström, 1900) in the beginning of the 20th century. The answer to this question may be found in the political ideology of centralized governance. This is also sometimes called "the new world order". The idea goes that if people have a one-world government, any kind of hostility or aggression, for instance wars between neighboring countries, will be avoided, because government-governing both sides of the dispute-will not allow it. While the objective is noble, it is questionable if it is possible to implement and if it is not throwing out the baby with the bath water. Meaning that it is destroying that what defines humanity, namely strife and competition. Without it, hu- 
manity is doomed. Nobody wants to wind up in an Orwellian dystopia.

A good indication is the political think tanks. We can identify one that had a clear agenda of a global governance, namely the Club of Rome. In their first famous book, Limits to Growth (Meadows et al., 1972), they presented the problem: the classic Malthusian Catastrophe of overpopulation of the world, also made popular at roughly the same time by a person of the same political persuasion, Paul Ehrlich, in his book The Population Bomb (Ehrlich, 1968). The idea was simple: The resources of the planet are limited and the population is growing exponentially. Somewhere something must go wrong, duh! Their case was so simple, everybody could understand it; it is not rocket science. Their ideas went viral. Even though their estimations of resources were way off-petroleum should for instance have finished by 2000 - it is undeniable that resources are limited. Ehrlich: "A shattering collapse of civilisation is a "near certainty" in the next few decades due to humanity's continuing destruction of the natural world that sustains all life on Earth". (Note that the "near certainty" proved to be equal-to-zero probability, as evidenced by you, the reader, reading this text).

Having presented the problem, they worked on the solution. Or, rather, having determined the desired solution (world governance), they worked on finding the necessary problem. They soon came up with it and presented it in their book The First Global Revolution (King \& Schneider, 1991). In it they presented a way how to control society: People should be made aware of the Malthusian Catastrophe looming over us and that it was important to join forces to avoid it. A way to join us was suggested in the use of climate change as a binding factor. Meaning, if it was not true, it should be invented-a convenient lie-for the benefit of the planet and humanity. They wrote (King \& Schneider, 1991)

The common enemy of humanity is man. In searching for a new enemy to unite us, we came up with the idea that pollution, the threat of global warming, water shortages, famine and the like would fit the bill. All these dangers are caused by human intervention, and it is only through changed attitudes and behavior that they can be overcome. The real enemy then, is humanity itself.

The idea that this goes hand in hand together with world governance may be trivial. Imagine we do not have one world governance, but two half-world polities. This then means that they are competing with each other for limited resources on the planet, and that means that one of them will win, the one who does not play nice. As Garrett Hardin has shown in his classic work, Tragedy of the Commons of 1968 (Hardin, 1968), there is no way of all behaving nicely; in such a world, the selfish opportunist will win. According to Hardin, the problem "requires a fundamental extension in morality". So either there is one world government of playing nice, or the playing-bad half will take over the playing-nice half (and we will destroy the planet). World governance is essential.

The above paragraphs can be considered as merely a theory. We will not set 
out here to prove nor disprove the existence of such a global "conspiracy" to take over the world, even though globalization has played a pivotal role and still is playing it, as for instance described by Rancourt (Rancourt, 2019) who observes the importance of the fall of the Soviet empire. The entire idea of talking in terms of conspiracies is absurd. In popular conversation a conspiracy thinker is someone that does not believe the narrative of the government. Yet, "conspiracy" being defined as "two or more people meet to make plans to change the world to their liking" or "to act in harmony toward a common end" (Webster dictionary), all politics is per definition a conspiracy, and the existence of people with an ideology that think of themselves intellectually and morally superior to the others and thus having the moral obligation to impose their ideology unto others (e.g. conspiring to replace the government by members of the conspiring party in next elections) is rather the order of the day; demands for regime changes galore. What we will do here is find out if such an ideology, irrespective of who or what is driving it, is desirable or even possible to implement. In no way does morality enter into our analysis or discussion, as morality does not follow logic or laws of physics. We will first present the role of energy in the economy. Then the role of money in the economy. And, finally, the role of politics in the economy. All based on three simple postulates which by themselves are self-evident.

In the next sections, we will first describe the role of energy in the economy (Section 2). Why quantifying the economy in terms of energy makes much more sense than expressing it in terms of any fiat currency. In this part the three physical postulates are presented. In the next section (Section 3) the role of the financial system in the economy is presented. Specifically the system of fiat currency as compared to an energy-based currency such as gold. Finally the role of politics is discussed in Section 4 and the implications in Section 5. A discussion section closes the work.

\section{The Role of Energy in the Economy}

The first important observation we have to make is that economy is not about money, whatever they may tell you. A GDP (gross domestic product) in terms of euros or dollars is not very meaningful. It is just a number (that can, as we will see, be adjusted at will). The important definition is here that

Postulate I: Economy is energy consumption

The unit of economy is joule per second (watt).

That is, economy deals with energy spent. As Georgescu-Roegen writes (Georgescu-Roegen, 1971), this energy is free energy and not latent energy (as for example the heat of an ocean). Ayres calls this free energy "exergy" (Ayres, 2001). We "consume" free energy by irreversibly converting it into entropy (chaos or disorder), from where it cannot be converted back into free energy. Scarcity of a 
material merely means that a lot of energy has to be spent to gain it. A block of pure copper costs less to "mine" than tons of copper ore that contains the same amount of copper atoms. "[C]ommon sense caught the essence of the idea in the parable of the needle in the haystack long before thermodynamics came to the scene of the accident" (Georgescu-Roegen, 1971). Furthermore, modern economists and politicians alike like to talk about a "sustainable economy", which before was called a "circular economy", meaning that the system is a closed box. This indeed is true, all atoms stay in the box and none are added. However, it is not true for energy and entropy. Energy is flowing into the box (from the Sun) and going out and entropy is constantly added to the planet and the universe. "One need only thumb through an ordinary textbook to come across the typical diagram by which its author seeks to impress upon the mind of the student the circularity of the economic process... No other conception could be further from a correct interpretation of facts. Even if only the physical facet of the economic process is taken into consideration, this process is not circular, but unidirectional" (Georgescu-Roegen, 1971). The critical questions about the energy theory of value, as mentioned by Daly (Daly, 1986), will also be answered here in this manuscript. It combines physics, biology and economy.

The point to make is that the unit of economy is not any currency circulating, because that is just a number and has no rigid connection to the real world. To give an example: if a bank transfers one million euros to another bank, and next day the bank transfers it back, we might count this as two million euros of economy. This is obviously absurd and economists have come up with a way to overcome this absurdity, namely by only counting added value in the production and trade processes. Bank transfers do not add value, and thus do not count for the GDP. Well, this immediately causes doubts, since we have learned from the financial crisis of 2008 (in Europe) that banks can, and indeed do, create added value simply by (re)packaging and selling (transferring) financial products. Examples are CDSs (credit default swaps) and CDOs (collateralized debt obligations) to name but two. Or to put it in another simpler example: The house prices have gone up in most countries. That means that the sum of values of the exact same houses have gone up, added value has been created somewhere in the economy, although the world is physically the same. Something is amiss here. And amiss it went in 2008. That is all history. The difference between market value and intrinsic (energetic) value is called "speculation". The correct way to analyze the economy is by energy. That is, how many joules are consumed. That is, an economy is sized by the amounts of joules spent per year, in other words: watt.

This was already observed by the classic economists, Ricardo, Smith and Marx. As Judson writes "It is argued that the embodied energy theory of value is very similar to neo-Ricardian economics" (Judson, 1989). It was actually already coined by William Petty, who continued the work of Aristotle: "All things ought to be valued by two natural denominations, which is land and labor" (with land 
simply the matrix for labor to work on). It is called the labor theory of value (LTV). Modern LTV argues that "the value is determined by the total amount of socially necessary labor required to produce it" (Wikipedia, 2020b) (emphasis by author). We use a definition here that is physically more correct-Energy Theory of Value (ETV) - that is more in-line with the classics and well described by Georgescu-Roegen. The value of a product is the toll and labor it has cost to bring it to us, see Table 1. Or in the words of Adam Smith (Smith, 1776) from the point of view of a seller on the market:

The value of any commodity, therefore, to the person who possesses it, and who means not to use or consume it himself, but to exchange it for other commodities, is equal to the quantity of labor which it enables him to purchase or command. Labor, therefore, is the real measure of the exchangeable value of all commodities.

"Toll" and "labor" are quite archaic, pre-modern science, words. Marx wrote about Arbeit, the German word for work. We still speak in terms of workers, as in "where do you work?" The physical term of "work" has become a social term in society; social sciences trying to monopolize the discussions in Economics and forgetting the classic works of, for instance, Adam Smith. Some people thus understand that work is uniquely something done by humans, but that is an unjustified limitation to the concept of work as meant by LTV. We should not ask "Where do you work?" but rather "Where do you do work?", as in "Where do you apply it?" A subtle difference. Moreover, "work" or "Arbeit" is simply the force multiplied by the distance over which the force is applied. Moving an object one meter with a force of one newton is one unit of work. And, this unit newton-meter is exactly the definition of joule! Another physics word that got a social connotation is "(work)-force" which we use for the arsenal of workers. This force (unit: $\mathrm{N}$ ), when given something to do and apply this force with a speed $(\mathrm{m} / \mathrm{s})$ contributes to the economy $(\mathrm{Nm} / \mathrm{s}=$ watt). In other words, economy is the amount of work done in society per year; energy per unit of time, thus "watt". This work, however, is not only done by humans, but by entire society. A machine is also doing work and thus also contributes to GDP. In fact, most work in the 21 st century is done by machinery. We have about 40 mechanical slaves working for each of us (Jankovici, 2005).

The price (value) of a product is thus energy, and many people have observed this. Take for example Scott, writing in 1933:

Table 1. Definitions of value.

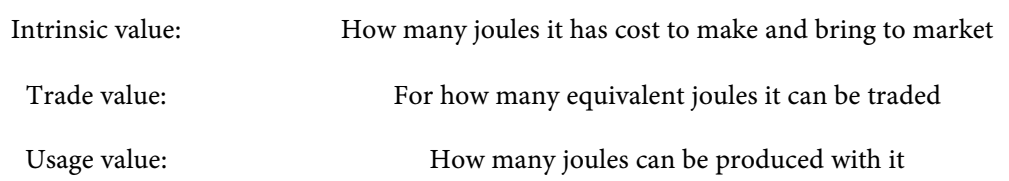


"It is the fact that all forms of energy, of whatever sort, may be measured in units of ergs, joules or calories that is of the utmost importance. The solution of the social problems of our time depends upon the recognition of this fact. A dollar may be worth-in buying power-so much today and more or less tomorrow, but a unit of work or heat is the same in 1900,1929, 1933 or the year 2000." (Scott, 1933)

Berndt later writing about Scott: "Scott and the fascinating Technocracy movement he founded proposed that dollars and money be replaced by energy certificates denominated in units such as ergs or joules, equivalent in total amount to the appropriate national net energy budget, which could then be divided equally among all members of the North American Continental Technate" (Berndt, 1981). This, however, is not needed, as will be shown, since gold is an energy value too and thus serves as a good reference value in economy (as long as the energetic cost of delving a kilo of it remains constant).

The values given in Table 1 are

Intrinsic value: How much (free Gibbs) energy it has cost to bring to the market.

Trade value: If we go to the free market, all offered products have a certain intrinsic value. And they should ideally be traded on a 1-to-1 joule-for-joule basis. However, if the market is not efficient, it can occur that we can make profit. We can trade a product that has cost $x$ joule to produce and trade it for $y$ joule, which can be lower or higher. $y$ is the trade value of our product. Usage value: If I buy something on the market that can be used for producing more products to be brought to the market, this has usage value. For instance a sieve which helps me mine gold. The sieve has trade value, but also usage value. We can also see this as investment.

Pleasure value: Seemingly a non-quantifiable "emotional" value, it is basically the usage value, not for producing more capital or products, but for producing more humans, or whatever entity the "pleasure" applies to. A self-usage value. Not $\mathrm{H}$ (uman) using $\mathrm{U}$ (sage value) producing $\mathrm{T}$ (rade value) but $\mathrm{H}$ using $\mathrm{P}$ (leasure value) to produce $\mathrm{H}$.

As we will see now, this system inherently drives the consumption (of joules) up. The social perspective of driving force behind the power (watt) increment of economy in a free market is the need to increase personal "pleasure". Optimize the personal state of the agents in economy. (For the moment, this metaphor will do, but we must comment on it again. It somehow places consumers, especially humans, on a central position and while many philosophies tend to focus on a privileged position of humans, science must abdicate from this arrogance. When we read "human" we should simply think "agent"). Trade is driven by the concept summarized in this postulate:

Postulate II: Free market

In any trade on the free market, both parties are happy. 
So, two agents (people) exchange goods (joules) if both either

- have direct increase in "happiness",

- can increase their amount of (tradeable) joules for future conversion to "happiness".

The former we can call "consumers", the latter we can define as "capitalists" that talk in terms of "usage value" and "profit". Consumers talk in terms of "pleasure value", their increase in their "state" (whatever that is).

The concept of "happiness" is undefinable (has no S. I. unit, and thus does not exist), but we can make here a small biological sidestep in making the observation that happiness is the fuzzy definition of driving force to survival and reproduction; increasing the number of people, the amounts of people (unit: mol). Happiness is just the chemical sensation programmed in our genes that tells us we are having a good strategy to survive and reproduce, the natural selection theories of Darwin then taking care of the rest to have the ones with best strategies occurring in highest amounts (mol). It is quite basic; when I eat a good lunch, my belly is full and I will survive a couple more days, in which I have a chance to reproduce. Other pleasures can be on a longer time scale. Buy a car to improve the chances to find a mate. When we read "happiness", we can thus think "good path to increased number or amount (mol) of consumers". It is even the central tenet of the philosophical school of Utilitarianism of Jeremy Bentham (1748-1832) and John Stuart Mill (1806-1873) who aim for "The greatest good for the greatest number" (Probe, 2019), which is an (Ethics) philosopher's way of stating the physics law of tendency of maximum consumption of energy (by increased number of units (mol) and increased consumption per unit $(\mathrm{W} / \mathrm{mol})$ ), or in other words, since consumption of energy-conversion into heat-increases chaos in the world, and entropy is the measure of chaos. We reach the third postulate:

Postulate III: Thermodynamic economy

The natural objective of the world is to increase entropy.

This postulate is not something new. It is also not a new concept to link physics with economy. As Georgescu-Roegen writes "Every subsequent development in thermodynamics has added new proof of the bond between the eeonomic process and thermodynamic principles. Extravagant though this thesis may seem prima facie, thermodynamics is largely a physics of economic value" (Georgescu-Roegen, 1971). In other words, thermodynamics is the physics laws of economy, and economy is the anthropomorphic description of the laws of thermodynamics. Or, as he writes, "[T]he" basic nature of the economic process is entropic and [...] the Entropy Law rules supreme over this process and over its evolution".

The biological reality is that species that produce more entropy (those that consume more energy) are those that are driving out those that don't manage do 
that so well. England calls this phenomena Dissipation-Driven Adaptive Organization (England, 2013), well described by the blog of Memo Akten (Akten, 2020):

According to England, life arising and evolving is a fundamental law of nature and "should be as unsurprising as rocks rolling downhill". In fact he claims "You start with a random clump of atoms, and if you shine light on it for long enough, it should not be so surprising that you get a plant."

You see, you could take the same atoms that make up you or me, and re-arrange them in a different way, so that it is not a living, breathing human, but just a lump of carbon, nitrogen, oxygen etc atoms. From a physics point of view, the one thing that living things do better than the same molecules re-arranged differently (i.e. not living), is that they capture energy from their environment and dissipate it as heat more efficiently.

From the article ([emphasis is Memo's]): “[England] has derived a mathematical formula that he believes explains this capacity. The formula, based on established physics, indicates that when a group of atoms is driven by an external source of energy (like the sun or chemical fuel) and surrounded by a heat bath (like the ocean or atmosphere), it will often gradually restructure itself in order to dissipate increasingly more energy."

A human eats the produce of the land and converts it into useful work and also part is used to produce more working units. “... clearly, it is much more likely that one bacterium should turn into two than that two should somehow spontaneously revert back into one. From the standpoint of physics, this observation contains an intriguing hint of how the properties of self-replicators must be constrained by thermodynamic laws, which dictate that irreversibility is always accompanied by an increase of entropy" (England, 2013). We thus use here "working unit" not as a deriding term for humans, but used to make it more general. Work is applied to give birth to more humans, but also to produce machines and tools-capital-to speed up the entropy maximization. With better spending of energy, more working units can be produced. Societies that had more capital (tools) were more efficient and created more working units, in the form of humans and capital and destroyed or substituted other, (thermodynamically) inferior, societies. The distinction between humans and capital gets further blurred. Some economists even speak of "human capital", which makes perfect sense in view of the above. Even so, we stick to the above definitions of humans/consumers and capital.

The entropy efficiency of a human is rather low. A person eats on average $3000 \mathrm{kCal}$ of food on a daily basis, a cal is $4.12 \mathrm{~J}$ (a Cal is $4.12 \mathrm{~kJ}$ ) and we thus have some $12 \mathrm{MJ}$ of energy input in 24 hours, that is about 140 watt. A lot of energy goes into maintaining the working unit (heating, repair of faulty [sick] units and energy conversion [a.k.a. digestion]), only a fraction is used for "useful" work. This demonstrates a bottleneck for human expansion. It is marginal, at best, even if circumstances are optimal, such as were found in warm-climate 
epochs (for instance the Medieval Optimum). When natural conditions were adverse, even a rapid decline set in. Energy was not sufficient to maintain the working units and populations were decimated (for instance in the Little Ice Age).

Technology has improved conditions and has tipped the scale in favor of human expansion in any climate condition. Houses were built. Houses were heated. Sanitation and health care reduced the drop-out rate of faulty units. Moreover, humans started harnessing nature and a lot more energy got available to them per person. At first this was only harnessing of environmental energy sources; windmills and watermills. An industrial revolution started where mechanical power, other than human, was used for producing capital and consumption goods. Human power was alleviated and could be used to reproduce more, and the combination of increased number of humans and the increased consumption of energy per human meant that entropy production of the human species was rapidly rising and we soon started driving other, less efficient, species out. Yet, again we reached a bottleneck. The amount of environmental energy that can be harnessed was rather limited. There is only so much solar energy that can be converted into useful work by windmills, watermills, bio-fuels (e.g. tree burning), etc. The efficiency is in the order of a percent of sunshine power. Countries were laid barren by the wood consumption. An example is Holland (etymology: old Dutch Holt Land, or Wood Land), a province of what is now called The Netherlands, that cut all the trees for heating and building their ships used in establishing their world empire. Not many trees standing in the 21st century in The Netherlands.

However, soon a new wave of harnessing nature started. Man discovered fossil fuels and the supply of energy by this new energy carrier is effectively unlimited. Man had discovered manna from heavens. One may think fossil fuels are limited (those that speak of "peak oil", etc.), but that is simply market manipulation (speculation) of those that control the reserves and simply want to barter a better deal. Fossil fuel reserves suffice for at least 100 thousand years, as can be calculated on basis of the fact that initially $25 \%$ of the atmosphere was carbon dioxide and this was all converted into fossil fuels. So the theory goes.

Since the discovery of fossil fuels, even in relatively adverse climatic conditions (from which we are slowly emerging), humanity has thrived as never before. Population has nearly quadrupled in the past century, in spite of two devastating world-scale wars (an unfortunate side effect of the strife to obtain resources to make tribes reproduce and grow as described above; the growth of one is to the detriment of another, be it other humans or other species altogether).

It is also obvious that the societies that consume more energy are also the ones with the highest wealth per capita. There is a near perfect correlation between energy consumption per capita, and GDP per capita (Geological Society of London Blog, 2019; Agency, 2020) at a particular moment in time, see Figure 1 that shows the correlation for 2015. It shows that the world is crystallized into a system where 


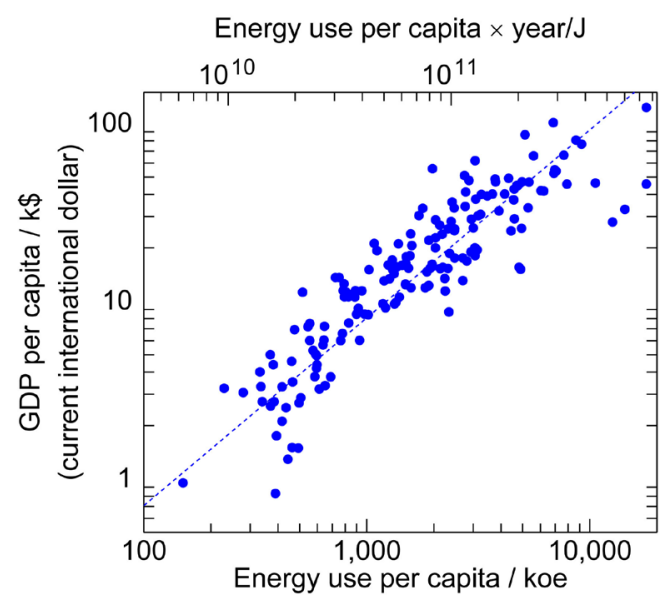

Figure 1. Correlation between energy consumption and GDP of countries in 2015 (each dot is a country) in a double-logarithmic scale; the slope-1 inclination of the line demonstrates a linear relationship, GDP linearly proportional to energy consumption. Data source: The World Bank, 2020. $1 \mathrm{~kg}$ of oil equivalent (koe) is equivalent to 41.868 MJ (Juggler, 2020).

energy is money. We can make a very important observation here: Because of this link, at any moment in time,

If something is energetically viable (profitable), it is economically viable (profitable), and vice versa.

We will use this in the analysis.

Note that the monetary unit for GDP is current international dollar; corrections have to be made to GDP because of effects of inflation, a deliberate lowering of the buying power of money, made possible by abolishing the gold standard. To show you how this works, consider this meme: "In 1964, the minimum wage was five silver quarters. In 2016, 5 silver quarters have a melt value of $\$ 15.55$. We do not need to raise the minimum wage. We need to fix the money" (Gold, 2020).

We also must avoid the discussion of cause and effect in Figure 1. Energy and economy are simply linked and equivalent (within the margin of error in statistical reporting) with a linear relationship between the two as demonstrated by the unity slope of the fitting line in a log-log plot. Garrett estimates a correlation of $9.7 \mathrm{~mW}$ per inflation-adjusted 1990 US dollar (Garrett, 2011), while our estimation from the figure is $170 \mathrm{~mW}$ per current (2019) international dollar. An increase of energy consumption is not only the law of nature, but also desirable. Curtailing it is foolish and will cause widespread poverty. The other direction seems more promising, stepping up in the Kardashev scale (Kardashev, 1964). We are now close to being a Type-I civilization on that scale, also called a planetary civilization; we can use and store all of the energy available on our planet. A Type II civilization will use and control energy at the scale of its stellar system, while dreaming of becoming Type III is for the moment very far-fetched, controlling energy at the scale of the entire galaxy. 
As Garrett concludes after having observed a quite stringent relation between energy consumption and economy, just as we did here, "This important constraint, and the fact that [the parameters] have historically varied rather slowly, points towards substantially narrowed visions of future emissions scenarios for implementation in global circulation models [i.e., energy consumption and climate predictions]" (Garrett, 2011).

Thus, economy is energy consumption (and converting it into heat $=$ chaos $=$ entropy), and moreover this energy consumption has to grow because that is the natural law, and also a financial law, as we will see. We can now argue that we are somehow "above nature" in that we are the only species in history gifted with intelligence and that we can avoid the Malthusian Catastrophe by careful planning. That we can somehow avoid (exponential) growth and reach some kind of steady state. Is this possible?

Before we answer that, we must first make an observation that if the society is to consume less energy in total by reducing the energy used per consumed product, there is already a very efficient mechanism in society to achieve that: It is called the free market. In a free market agents trade goods. In their Smithian selfish interest-allowed by the freedom of the market-they want to be happy in a trade, and that means that they want to exchange lower-energetic goods for higher-energetic goods, if they can get away with it (see the postulate on free trade). Or, in other words, they want to get more-energetic products or more of the goods in the trade. The way they go about is trying to lower the (energetic) cost of production of the goods they offer and exchange them on the market. As long as the market is not yet adjusted to this new energy-efficient way of production, there is some speculation in the market and the products of this agent are overpriced. Other agents, when they get a whiff of it, try to copy the production methods and also lower their production cost (in terms of energy). Or the agent itself produces more and the increase of offer lowers the market price. All this, until the market settles again in the correct exchange rate. The eternal greedy obsession-or obsessive greed-of the agents is the driving force behind the never ending down-spiral of production cost, a driving force to consume less energy. (Maybe the reader finds this paragraph strange. But, replace the word "energy" with "money" and it'll sound perfectly correct in any Economics textbook. Combine this with the fact that money equals energy [shown here empirically in Figure 1 and linked through the gold standard to be discussed in the next section] and the paragraph makes perfect sense). The conclusion is that in a free market there is a natural driving force to reduce energy consumption per product.

On the other hand, any species has a biological driving force of increasing the total amount of energy consumed (read: entropy produced); increasing the number of products and number of consumers (or generally speaking: entropy production units). Human society is the most efficient system to play on both sides, lowering the energy of goods, and increasing the number of goods and, consequently and besides, increasing the number of biological and non-biological 
moieties to consume these goods. Just that we humans are conscious of the laws of nature does not make us able to surpass the laws of nature. We must assume we are biological entities just like any other, following the same laws of nature. Economists want to avoid jargon of the natural-sciences and have coined their own terms, such as "money" and "economy". This will be discussed in the next section. How money is linked with energy in our real society.

\section{The Role of the Financial System in the Economy}

Originally, money-any form of payment for goods traded-was the goods themselves. That is, in bartering, goods were directly exchanged. This is rather inconvenient for various reasons. Goods may not always be available at the same time at the market (imagine spring fish and autumn grain), and most goods were perishable. For this reason gold or silver was often used in trading, originally probably also as direct barter. Soon it also took the function of "storage value", one could keep it for later trade. This is the advent of the concept of money. And, as Winiarski writes, underlining the LTV, "Gold is therefore the general social equivalent, the pure personification and the incarnation of the socio-biological energy" (Georgescu-Roegen, 1971). Gold is linked to energy and thus to labor theory of value.

It has to be pointed out that gold was initially no different than any other good. It represented an intrinsic value (as mentioned in the previous section). $A$ certain amount of gold represents a certain amount of energy to mine it, mint it and bring it to the market. On the market, however, the trade value is determined by supply and demand. We can thus have effects of speculation, when goods are not traded in the ratio determined by their intrinsic (energetic) values. In some cases, this speculation is fomented by special agencies. For instance OPEC (oil-producing and -exporting countries), who want to increase the market value of oil by inventing and propagating the idea of scarcity of oil; take as an example the eternal prediction that oil will end in 30 years. See for instance the before-mentioned book of The Club of Rome who said in 1972 that oil would be finished around the end of the millennium (Meadows et al., 1972).

Adam Smith, in his classic work (abbreviated as) Wealth of Nations (Smith, 1776), argued that in a free market, if everybody acts purely in his own interest, this is (often) good for the whole community. Thus contradicting the ideas of Hardin mentioned in the previous section; the exact selfish morality is what is argued to be good for the world. In this specific case, if, for instance, gold is overpriced at the free market relative to grain, that is, more joules of grain can be bought with less joules of gold, people (farmers) will apply their power (watts) to delving gold instead of growing grain. This will increase the supply of gold, whose trade value will thus drop, and lower the supply of grain, whose trade value goes up, until at the end goods are traded at equal-joule ratios again. This assumes a free market, with moreover all agents having all the information needed to make decisions, in a so-called efficient market hypothesis (EMH) (Wikipedia, 2020a), which we assume here. 
There is now a technical problem, as already mentioned by Socrates to Plato: There are two types of people on the market. Those that enter the market for qualitative exchange, and those that enter the market for quantitative exchange. The former offer their products, for instance grain, and exchange them for something else, for example wine, facilitated by the help of gold:

Qualitative: grain $\rightarrow$ gold $\rightarrow$ wine.

Note that this directly increases entropy. The situation in which one trader has all the grain and another all the wine has lower entropy than the products being distributed evenly among them. We can even here observe the natural laws in the economy. Trades tend to increase entropy and we can even propose it is always the case.

The latter type of people on the market are so-called "traders", and enter the market with one product, for instance gold, buy and sell products, and leave the market with more of the same gold, at least that is the objective:

Quantitative: gold $\rightarrow$ \{grain, wine $\rightarrow$ more gold.

This is bound to go wrong. For a simple reason that the amount of gold is limited. If quantitative traders have a gold-profit objective, or otherwise will not enter the market, they will accumulate all the gold, after which the market halts and poverty strikes; No trades take place, not even by qualitative traders, who also need gold! This is what happened to king Midas, who saw all his gold gone from his coffers and his economy slumping. His solution was fiat currency (stamping brass coins with his emblem, declared to be of equal value as gold). More on fiat currency later.

Capitalism is the total-market equivalent of Greek quantitative gold-based traders. Capitalists enter the economy to create more capital. Capital is defined as products (joules) not meant for consumption, but for production. Capitalists talk in terms of "profit", something that does not make sense in qualitative trading since it is comparing apples with pears, possibly even literally. Yet, as already mentioned in the previous section, this capital is not only gold, but anything that represents, or can be used to create, wealth (see the free-market postulate). It includes factories, stocks of merchandise, land, intellectual property, human property (slaves), real estate, etc. Anything that is not consumptive goods, see Figure 2. Such objectivism is ideal for society, since it also increases means of production, and if consumptive goods are a fixed percentage of all goods produced, generating more means of production will increase the amount of consumption goods produced and thus increases our living standards, which will increase exponentially:

$$
\begin{aligned}
& \frac{\mathrm{d} M(t)}{\mathrm{d} t}=K(t)=\alpha \beta M(t), \\
& C(t)=\alpha(1-\beta) M(t) .
\end{aligned}
$$

( $M$ is means of production (MoP, unit: J), $K$ is capital gain (unit: J/s), $C$ is consumption goods (unit: J/s), $\alpha$ is efficiency of MoP (unit: $1 / \mathrm{s}$ ), $\beta$ is fraction of MoP dedicated to increase MoP, unit: 1). This differential equation has as solution 


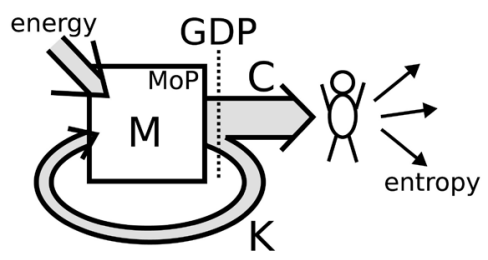

Figure 2. Means of Production (MoP, $M$ ) are used to make capital ( $K$, more means of production) and consumption goods ( $C$, that are converted into entropy by consumers). Both $C$ and $K$ contribute to GDP.

$$
\begin{aligned}
& M(t)=M_{0} \mathrm{e}^{\alpha \beta t}(\text { unit : J }), \\
& C(t)=\alpha(1-\beta) M_{0} \mathrm{e}^{\alpha \beta t}(\text { unit : J/s). }
\end{aligned}
$$

Note: On the short term, consumers want to lower $\beta$, implying instant consumption (driven by the natural force to increase entropy), but on the long run it is always beneficial to increase the fraction $\beta$ of means of production used in creating more means of production, see Figure 3 . The power of unfettered capitalism. Empirically, the profit to capital is of the order of $(\mathrm{d} M(t) / \mathrm{d} t) / M(t)=\alpha \beta=5 \%$ per year and this is remarkably constant over time (Piketty, 2013). While the need for profit for the capital is obvious, we have no explanation for why it should be exactly $5 \%$.

In a simplified picture of the energy theory of value (ETV): energy, through the means of production, is converted into more means of production and consumption products. These latter are by definition those that are converted by humans into entropy. Entropy being a measure of heat or chaos, the driving force of the universe, including humans and their economy, is to increase it. In this cycle the other ingredient that economists often use, "raw materials", has been fully ignored, since they are just the matrix on which the economy game takes place. No atoms, whatsoever, are created or destroyed by economical activity. What comes in goes out. Full stop. The only thing that changes is the state of these atoms, namely one in which the entropy has increased.

Note that waste (of which more later) has been ignored; all production is $100 \%$ efficient and either produces consumption goods or capital. Note also that in this picture the contribution of humans to production has been ignored for clarity. In fact, humans also contribute. Arrows K' and C' should originate from the humans, representing production of capital and consumption goods, respectively. We could also lump these human units with the capital; a human has a net worth of about 2 million dollars on average, so we can see humans as "human capital" in the means of production (MoP). (For physics it matters nothing who exactly is doing what, that only is a field of study of social sciences, which we avoid here). However, humans will even enter into production when making a loss just so as to minimize that loss, since their spending of energy is constant (140 watt). There where other capital, in the framework of capitalism, only produces when it makes profit, or has an outlook to such. If, however, somebody else decides if the human is producing or not, this production will be stopped and the human production unit will die of misery. (Thus spoke Marx). 


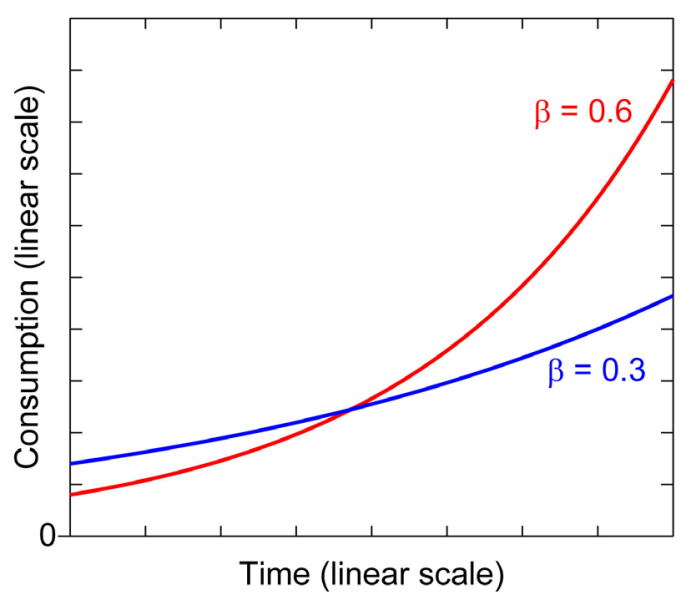

Figure 3. The fraction $\beta$ of means of production used to produce more means of production should be as high as possible; even when initially consumption is low, at the end, unfettered profit-driven economy wins over direct-consumption-driven economies. (See Equation (2)).

All production combined is the GDP. This is the sum of capital gain $K$ and consumption goods. From the figure it is obvious that the only correct unit of GDP is energy per time unit. No euro or dollar or yuan is a good unit to express the economy in, for reasons that will become obvious in a moment. They represent nothing else than a number and, like the realm of mathematics in which they reside, numbers only pertain to virtual, imagined worlds. The real GDP is defined as

$$
G D P(t)=K(t)+C(t)=\alpha M_{0} \mathrm{e}^{\alpha \beta t}(\text { unit : } \mathrm{J} / \mathrm{s}) .
$$

And this has a unit of joule per second or watt, or koe/year, or any other energy unit divided by any other time unit.

The problem now resides in the fact that the planet is finite there where the economy must grow indefinitely; The driving force of economy is the existence of $K$, without it, capital will stop production. The system reaches a point where resources become scarce and physical growth is no longer possible $K=0$. If capital produces on basis of creating or accumulating more capital-that is, profit $K$ is positive $-M$ must grow. Once it reaches the point it cannot grow anymore, the capital stops production altogether and we enter a marxian crisis of overproduction with idle means-of-production existing alongside an angry mob of needy consumers. First capital starts to concentrate: "companies" first start to go bankrupt and merge to the point where only a few are left that no longer compete with each other; about seven (Stallinga, 2017). Moreover, all wealth (joules) is taken away from people, since it was effectively used as barter in the exchange of goods to sustain the human life. How does that work?

Enters the third type of market participant, the banker. A banker is a special type of quantitative trader. It does not use goods to exchange and make profit, it uses money itself to make monetary profit, never are different goods exchanged. See Table 2. 
Table 2. Types of traders in a market.

\begin{tabular}{cc}
\hline Qualitative trader: & $A \rightarrow B$ \\
Quantitative trader: & $G \rightarrow\{A, B\} \rightarrow G^{\prime}$ \\
Banker: & $G \rightarrow G^{\prime}$ \\
\hline
\end{tabular}

(A, B: different products, G: gold money, G”: more gold money).

Banker: gold $\rightarrow$ more gold.

Bankers lend out money (gold) on the market with an objective to accumulate more money; they are not interested in other forms of capital. This is, however, very good for society. It enables individual agents to start businesses and produce goods for society. Agents can get financing (receive gold) with which they can buy means of production to start businesses that profit the agents, but through Adam Smith's observation, also benefits society at large. The banker also benefits, by getting interest on the loan. Everybody happy.

That is, the banker, just like the quantitative trader, only enters the market-only lends out money—when it has an outlook on (gold) profit. As Daniel Kahneman analyzed in his book Thinking, Fast and Slow (Kahneman, 2011) when people take risk: It is simple, people want to be compensated for taking risk; the average profit should be positive, because people are not philanthropists (according to Smith). At zero risk, bankers still want to make profit and the profit must increase when the risk goes up. So, on average, a bank must make profit (accumulate gold), or it will not enter the market. Such markets in the absence of investments are called "crisis", which can be directly traced back to the Kahnemanian lack of outlook on profit in society. Politicians must thus create circumstances for capital to have a good outlook on profit, for instance by lowering taxes to companies, or actually guaranteeing profit in so called PPPs (private-public participations), which are a form of heads-you-win-tails-we-lose promises of the government.

And, as we argued, since the amount of gold is limited, the outlook of gold profit in reality must dwindle. Therefore, a crisis is inevitable, and this happened to Midas, but also to England in 1917 and later in the United States in 1971.

In fact, gold was already no longer used on the market in physical form, but rather in paper promises-"banknotes"-instead. These promises are what we traditionally call "money". Note that they still represented energy, albeit diluted by a factor of about 20 by opportunistic bankers who issued more promises than they physically owned gold in a scheme called fractional-reserve banking (FRB). First by the Bank of England and later by the Federal Reserve of the USA this "gold standard", the convertibility of money to gold, was abolished. Note that this is legally impossible. A banknote-any contract-must promise something, which is technically called "consideration". A contract without consideration is null and void. This is an essential observation, as we will see in a moment. However, by this illegal act, the central banks by now held the governments in these countries ransom and effectively govern instead of the democratically cho- 
sen representatives. Societies converted into a chrimatocracies, societies where money rules.

The gold standard has been removed, there where before 1 joule of money (gold) could be traded into 1 joule of any other product: A trader could enter with 1 joule of product $A$, sell it for 1 joule of gold, and then buy with that 1 joule of product B. Not any longer. First FRB money was introduced and the 1-joule-nominal money only represented 50 milli-joule of energy and could be traded only as such. Promises of 1 joule of gold only bought 50 milli-joule of goods, even in the absence of speculation. Somehow 950 milli-joules go missing from the accounts. One can smell a swindle. A bookkeeping trick, done by special accounting entrepreneurs that, we assume, work in accordance to Adam Smith, namely in their own interest. It is time to call bankers banksters. But, in effect, the market barely noticed anything, because $50 \mathrm{~mJ}$ of product $\mathrm{A}$ was sold for $1 \mathrm{~J}$ of gold promises, which then bought $50 \mathrm{~mJ}$ of product $\mathrm{B}$, at the end it looked like fair trade.

And then it got worse and money no longer represented energy altogether by the abolishment of the gold standard (see Table 3). The linear relationship between energy and GDP was lost, as also evidenced by Figure 4, which shows the evolution of GWP per capita (gross world product; sum of GDPs) vs. the energy consumption per capita of the entire world for years between 1960 and 2019. The sharp inclination shows that the GWP grew much faster than the energy consumption, which was made possible by severing the link between energy (gold) and money. If the link had persisted, the linear one-to-one correspondence between energy and economy would have maintained (the long-dashed black line in the graphic). Empirically, GWP is proportional to more-or-less the fifth power of energy consumption; if energy consumption per capita grows a factor 2, GDP/GWP per capita will grow a factor of $2^{5}=32$.

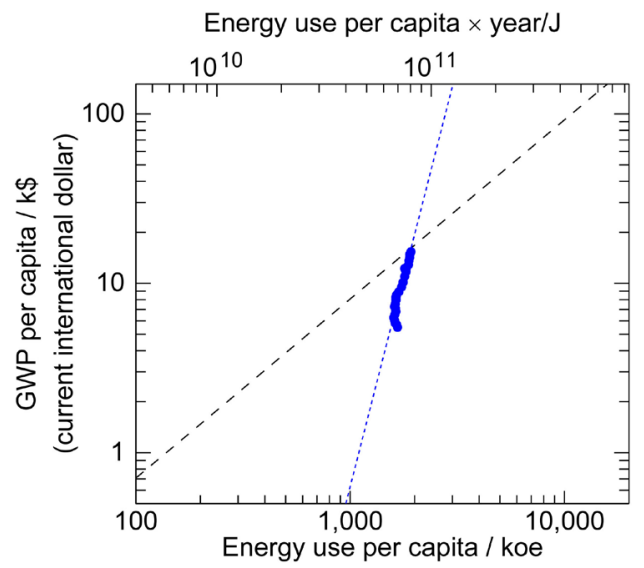

Figure 4. Correlation between world energy consumption and GWP from 1960 to 2019 (every point represents a year) in a double-logarithmic scale (same as used for Figure 1). The sharp inclination of the line demonstrates a fifth-power-law non-linear relation, GWP $\propto$ energy $^{5}$. A linear one-to-one correspondence between economy and energy would be the long-dashed black line. Data source: The World Bank, 2020. $1 \mathrm{~kg}$ of oil equivalent (koe) is equivalent to $41.868 \mathrm{MJ}$ (Juggler, 2020). 
Table 3. Types of money.

\begin{tabular}{cc}
\hline Original money: & $\mathrm{M}=\mathrm{G}$ \\
FRB money: & $\mathrm{M}=\mathrm{G} / 20$ \\
Fiat money: & $\mathrm{M}=0$ \\
\hline
\end{tabular}

(M: money, G: gold (joules)).

Imagine now that $\mathrm{I}$, together with my friends, have private companies united in a private banking cartel called Central Bank, and we are the only ones allowed to print money ("legal tender", form of payment that others must accept in trades). I do not have to own even a femto-joule of products, yet can confiscate all the energy in the world. I start by issueing 10 stallos (my own currency) and, since by now I am effectively in government, I make it law that no other currency can be used; I am the only one with legal tender. You want to buy a 10-joule house from your neighbor. The market price is 10 stallos (in fact, the price is determined before I issued the money); your neighbor naive as he is, trusts (has "fiat") that these stallos are worth something in the future, but anyway, there is no way out of this scheme, because my bank is the only one with legal tender. In the beginning your neighbor is the only one with assets, 10 stallos market value of a house that has cost 10 joules to build (market value is 1 stallo $=1$ joule). You come to my bank and I lend you the 10 stallos. You give them to your neighbor in exchange for the house. We now have the following situation:

\begin{tabular}{|l||l|}
\hline My bank: & You: \\
\hline owing 10 stallos to your neighbor & owing 10 stallos to me \\
owed 10 stallos by you & $\begin{array}{l}\text { owing } 1 \text { stallo interest to me } \\
\text { owed } 1 \text { stallo interest by you } \\
\text { owning a house with a market value of } 10 \text { stallos } \\
\text { book value: }+1 \text { stallo }(+1 \text { joule })\end{array}$ \\
book value: -1 stallo $(-1$ joule $)$ \\
\hline
\end{tabular}

\begin{tabular}{|l|}
\hline Your neighbor: \\
\hline owning 10 stallos of my bank \\
book value: +10 stallos ( 10 joule) \\
\hline
\end{tabular}

As you see, net no physical products were created (the sum remains 10 stallos) and no joules were added to the system. I did, however, immediately get 1 stallo from you; my Equity is 1 stallo. Part of it is risk (or is it?), but on average I will win (or not invest). Yet, out of thin air-I did not own anything before-I did not only print money, I am now the owner of part of the house! One might think that this is also a free market, and the 1 stallo "profit" represents compensation for work being done (energy being spent) and on the free market the offer of such services increase, as described before and the price for it going down, until 
speculation is gone. However, the Central Bank is a banking cartel and no free market exists (for which at least seven companies are needed (Stallinga, 2017), there where only one exists, one company with many branches). For instance, your other neighbor is not allowed to print the money. This is why the saying goes around, "Give me control of a nation's money and I care not who makes its laws", which might well have been said by Nathan Rothschild (though that is irrelevant).

Let's put this in bookkeeping balance sheets. An "asset" is what I own and what people owe me, a "liability" is what I owe people. To make the balance sheet balance, with the sum of all assets equal to the liabilities, I create a virtual (pseudo)liability called Equity, which is my net worth. Let's make a balance sheet for all parties involved, and let's call my promises to the market "banknotes", since they can anyway be traded on the market and do not necessarily remain in the hands of the first receiver. Let's also call the things you owe me "mortgage" ("principal" debt) and "interest":

\begin{tabular}{|l|l|}
\hline \multicolumn{2}{|c|}{ My bank: } \\
\hline Assets & Liabilities \\
\hline your mortgage, 10 stallos & 10 stallo banknotes \\
your interest due, 1 stallo & Equity: $+\mathbf{1}$ stallo (=1 joule) \\
\hline \multicolumn{2}{|c|}{ You: } \\
\hline Assets & Liabilities \\
\hline house (10 stallos) & mortgage, 10 stallos \\
& interest, 1 stallo \\
\hline & Equity: -1 stallo (=-1 joule) \\
\hline & Your neighbor: \\
\hline Assets & Liabilities \\
\hline 10 stallo banknotes & Equity: 10 stallos (= 10 joule) \\
\hline
\end{tabular}

There are now 21 (promises) of stallos going around on the market. Ten banknotes (my promises) initially in the possession of your neighbor that he can use to buy houses on the market and eleven promises of you in my safe, that I can also use on the market (for instance by selling it to another bank-CDSs and CDOs-which gives me banknotes of that bank in return). A house could now be worth 21 stallos and I can buy 11/21 part of it. Of course, I still promised $10 / 21$ part of it to your neighbor, or whoever has my 10 banknotes circulating on the market. Who is winning and who is losing in this scheme? Your neighbor has 10 banknotes, but that now is only worth $10 / 21$ of a house ( $=4.76$ joule). You gain big time! Your house is worth 21 stallos and you owe only 11 stallos, so $10 / 21$ house is yours ( $=4.76$ joule). I own $1 / 21$ of the house ( $=0.48$ joule). I had 
better not enter the house market (using my promises to you; I had better stay low), or the inflation will also eat away my wealth.

As can be seen from this example, wealth (joules) can be relocated at will, with the blink of an eye. It has nothing to do with entrepreneurship, but all to do with control. Even better, governments, which I control, will confiscate (tax) house owners and use that to prop-up banks. This will happen when governments are centralized and start interfering into the market, deliberalizing it. Yet, this is the way to take full control of the economy, and possibly a way to reduce the energy consumption-"save" humanity-(by creating poverty and misery), by a virtualization of economy, no longer representing joules, but stallos. Your neighbor was driven by financial gain-maybe with his 10 stallos banknotes he managed to make a whopping $10 \%$ profit, 1 stallo-and wound up losing wealth (lost more than half of his energetic net worth).

We see for instance how this scheme was used to confiscate the physical means of production in Greece and Portugal in the (induced) crisis of 2008 by exchange for empty promises. Greece lost its Piraeus harbor, Portugal lost its electricity utility (EDP) and postal services (CTT) to name but a few things. Japan has lost most of its assets traded on the stock market (NIKEI); "Bank of Japan owns $60 \%$ of nation's ETF [exchange-traded fund] market as of June 2016" (Bloomberg, 2019). Those who control the money can confiscate all wealth. It is important to observe that the scheme does not work with gold, or any other commodity, as base in promissory notes. If a bank lends out promissory notes of gold, the loan can be paid back by fulfilling the promise with gold. Gold that is physically available in the world, unless the bank has hoarded all of the gold in its coffers. Promises of real physical commodities can be lifted and the issuer of the promises declared bankrupt if the promises are not met. Not so for banks, who can stave off bankruptcy any time. Alan Greenspan (former Federal Reserve Central Bank president): "The United States [our government, as long as we decide so] can pay any debt it has because we can always print money to do that. So there is zero probability of default". U.S. government is so much controlled by the private Federal Reserve that many people think that the Federal Reserve is an institution of the U.S. state. It is rather reverse; the federal government in Washington is an institution of the Federal Reserve, in line with the words of Nathan Rothschild. By controling the money, central banks are the de facto managers of the government, the economy and society.

The problem is not that banks can print money out of thin air, which in itself is no problem, even though there is generally hue and cry when the people at large find this out. Everybody is free to make (false) promises, there is no law against it. Stupid is the person that believes the false promises. It is not even so that the banks are the only ones making these promises. When you buy a house for, say, 1 kilo of gold, you also make a promise (to the bank) that you will pay this amount of gold (which you do not have yet) sometime in the future. You "printed" money (a promissory note) out of thin air by signing a mortgage contract! 
Nay, the problem lies in the fact that these promises are empty, which is a crime in itself, and leads to situations as described above. Take a banknote out of your wallet and look what it promises, just above the signature of the central-bank president. Nada! Yet, as Upcounsel writes, "A contract without consideration is void because it is not legally enforceable. "Consideration" means that each party must provide something of value to the other party as designated by the contract terms" (upcounsel, 2019). Upcounsel continues: [Several elements must be present for a contract to be legally valid] (italics by author):

- One party has made an offer that has been accepted by the other party.

- An item of value will be exchanged for something else of value, such as goods, services, or cash.

- The contract refers to legal subject matter.

- Both parties have agreed freely to the contract, are mentally able to fulfill its terms, and are older than the age of consent.

Technically speaking, a fiat money banknote is not a contract, but rather a deed, which is a one-sided contract (only one side-the bank-promising something). However, this is a small detail. Also a deed needs to promise something: A deed is "a written instrument, which has been signed and delivered, by which one individual, the grantor, conveys title to real property to another individual, the grantee; a conveyance of land, tenements, or hereditaments, from one individual to another" (Farlex, 2020).

As argued, and easily demonstrated, fiat money is not something of value, nor does it promise something of value. This is easily demonstrated by pointing out that an infinite amount of money can be produced-as per declaration of Alan Greenspan-with a finite amount of resources. Fiat currency represents zero joules of work. It represents exactly nothing. Moreover, it is a swindle, because it allows for the confiscation of real physical assets, as shown above. Our banks lends you 1 stallo and tomorrow we want 2 back, or you lose all your assets. Which you will, because there are no 2 stallos in the world. And don't even think about going somewhere else, because there is no "somewhere else". "Worship the Lord your Bank and serve him only". (A parody on Luke 4:8).

Recently, negative interest has been taking presence at the markets. This proves, without doubt, that the markets are no longer free, or that the value of money is zero-or both. To understand why, consider this: If I lend you something of value, I run the risk of you not giving it back. I want to be compensated for that risk. If there is $x$ probability of you not giving it back ( $x$ necessarily greater than or equal to zero, since it is a probability; $0<x<100 \%$ ) I want at least $x$ interest so that, on average, I do not lose on my investments (to be more precise, $1 /(1-x)-1$ would be needed for that, but for small $x$ that is equal to $x$ ). Moreover, I also want some profit $y$, and since I am not a philanthropist, $y$ is also positive; $y>0$. So, total interest $i$ is positive, $i=x+y>0$. Even if I lend out something of negative value (imagine waste that costs energy to get rid of), the interest must be positive, because you, the borrower, will demand it, since you are not a philanthropist either and run the risk I will not be able to take back 
the negative-worth good. You want to give me back tomorrow more waste than you "borrowed" from me today. That means that for any intrinsic value $P$ (positive or negative), the interest is positive, except when the value of the borrowed good-the "principal" - is zero $(P=0)$, because in that case "guarantee" (complement of risk) times "interest" times "principle", $(1-x) \times(1+x+y) \times P$ does not give loss since it is equal to the principal $P$, also for negative values of interest $x+y$. Interest is actually a meaningless concept in this scheme. Negative interest is thus consistent with zero-worth money or is a sign of market manipulation.

In this section so far we have seen how the banking system enables a subset of society to take control of government of a country and all means of production. Moreover, assuming they have at least the same morality as we do-after all, they are human just like you and I-they feel responsible for the assets they have acquired, including the human lives they control, and thus feel the moral obligation to be the stewards of the world. In other words, the concentration of wealth and means of production gives the stage to an elite that feels the responsibility to see the planet as theirs and start managing it. The creation of a new-world order, or pan-global government, is a logical step in this sequence. The people at large are actually demanding the powerful and rich elite to take a leading role in responsibly stewarding the planet. It is just a ruse by the elite who also simply follow a scheme to maximize their own entropy production (by denying it to others).

As an example, where the morality of the elite is clearly visible, after the debt-crisis of 2008 in Europe, caused by systemic problems with banks that were "too-big-to-fail", the solution of the ones in power was not to break up the banks that were too-big-to-fail, but rather the contrary. Bank mergers galore (Davig et al., 2015; Davig et al., 2017; Insider, 2019). The reason why it happens is easily understood in the Smithian free-market framework: because it is profitable for those that enable it. Profitable now is not even any more profitable in capital (this profit has an end in sight), but profit in power and control. The objective is to be the final saintly Steward saving the planet from Malthusian doom. For that, all control has to be grabbed.

We could now think that, to avoid this, simply nationalizing banks might solve the problem. First of all, it'll solve nothing since the financial world and governmental structures are already so much interwoven that it would not make any difference any more. Moreover, even if we were to succeed in taking back control of the country by taking control of money-issuing agencies we'd wind up with the same problem: if the money promises something, that something must be limited (nothing can be unlimitedly available and have non-vanishing energetic value). If it is promising nothing, apart from it being illegal, it is second-level meaningless. That is because where fiat-money promises nothingness at least to another party (for instance to the state in an exchange of state-obligations and fiat-money between state and bank), state-money is promising nothingness to nobodyness. It is promises to oneself. 
The nothing-nobody-money will be used (by the state, this time) to control our lives-and is thus anti-libertarian-and thus winds up in a system where all our liberties are taken away; mankind will kill itself. People will not invest for capital gain if there is no capital gain to be had. Converting it into a monetary gain that is not accompanied by a physical capital gain is a mind-control trick that will not work in the long run. We now see it happening: in spite of all tricks in the book, negative interest, etc., the economy is slumping yet again. Germany-formerly the best pupil of the European class-is already in crisis (Express, 2020).

\section{The Role of Politics in the Economy}

Continuing the last paragraph. Imagine that we change politics to nationalize (central) banks. Giving a lot of power to government often corrupts the entities receiving the power, as history has shown us. We are, however, not far from this situation. Banks are government and governments are banks. To highlight this, remember that central banks (those that are responsible for tier- $\mathrm{M}_{0}$ money, the base currency in society), create money, not really out of thin air, but, as in the example above, as a loan. Money = debt, normally states exchange state-obligations for bank-notes. The basic mechanism is to exchange promises between bank and state. The state issues bonds, bills and notes, which are promises to pay money back to the owner at different maturing dates. The (central) bank "buys" these contracts, when it sees profit in it (there is a natural limit to this process). It does so by exchanging them with its own notes (that, as shown above, promise nothing). Now, if the banks are nationalized, how can the necessary money creation take place?! The state would exchange promises with itself, which only makes sense if the state is schizophrenic. It might simply issue notes, but whereas fiat-money still has some minimal form of base underpinning it, after all, people obviously trust it, state-issued money is utterly worthless. They are promises of nothing to nobody, as explained before.

Yet, the system sees benefit in nationalization of banks. With the interwovenness of states and banks anyway so high that the step is minimal, the major argument for state banks is indeed the role of stewarding of the planet by the elite. Wikipedia (entry: Public Bank (Wikipedia, 2020c)) writes (emphasis by author)

Increasingly, major international financial institutions are recognising the positive and catalytic role public banks can serve in the coming low carbon climate resilient transition. Further, international NGOs and critical scholars argue that public banks can play a significant role in financing a just and equitable energy transition (Marois, 2017).

(Note the curious coincidental link between bank [money] and energy). Thus, an important role is set for banking in politics, or politics in banking. They are now waving it in our faces that banks are in control of society ... and should be, because they can, and have a moral obligation to be in control. The citation at the end is from the Transnational Institute (tni), a synonym for global gover- 
nance-anti-nationalism-mentioned in the introduction; there referenced as merely a conspiracy theory, we have now reasoned the justification for it and proven its existence. Fair to mention, also opposition is encountered, for instance by the German Bundesbank: “The German central bank (Bundesbank) has to maintain market neutrality and cannot become a proactive advocate of climate action, Bundesbank head Jens Weidmann said" (Wehrmann, 2019). Yet, the same article continues (emphasis by author), "Martina Arnold and Olaf Storbeck write that the Bundesbank's position might clash with that of designated European Central Bank (ECB) head Christine Lagarde, who said tackling climate change would become a "mission-critical" priority at the ECB" (Wehrmann, 2019). There is a drive for control of society through a climate-action (whatever that is) policy. Banks are governance and governance is banking. Opponents of public banks say (Wikipedia, 2020c)

[It] would pose financial risks to states and municipalities. Among the risks that have been cited by critics is the significant amount of startup capital that would be needed to start a public-bank, and concerns over political influence, which could lead to corruption, self-dealing and risky lending.

This argument, however, is incorrect, since already in the privatized banking system, exactly this happened. Self-dealing is rather common practice in the 21 st century, for instance interest-free loans (Quantitative Easing) to the biggest companies which then use these to buy back their own shares. Risky lending is averted by a scheme imposed on society of heads-I-win-tails-you-lose. The risk is fully assumed by the society and not by the lenders, who only take the profits. If it goes wrong, money promised by the states is used to bail-out banks. The way central banking is organized is that most, if not all, money is backed by society at large, meaning that the startup-capital mentioned here for modern private banking is the entire society that is mortgaged to the central banks. Allegedly, Deutsche Bank, has 20 times the GDP of Germany as assets on its balance sheets (CNBC, 2016). If something goes wrong, the German citizens have to tip in and work 20 years for free, to pay it all back.

\section{The Implications}

We now reach the basic three questions for this political-economic study. Karl Marx having shown that an energetically-indefinitely-growing economy is not possible in a free market, since it will lead to a crisis of overproduction in which a need for consumption goods exists alongside an idle infrastructure capable of supplying them,

1) Is it possible to have an (energetically) growing free-market economy after an energy transition? Meaning after switching from fossil fuels to renewable sources, can we have a biologically-viable sustainable growth?

2) If not, is it possible to have a constant-energy economy in a free-market with some banking scheme, or do we need a marxist-centralized-government economy? Can a biologically-viable steady-state be achieved? 
3) If not, can we solve the problem by lowering the population on the planet in a free market?

We have all the ingredients to answer these questions.

We start with the observation (free-market postulate) that in a free-market, people (capital) invest with the objective of making profit. Let's face it. Would you invest your capital if tomorrow you get less of it back than you have today? It would be better to keep it aside and wait out the bad times, wouldn't it? Such a situation is called a crisis. As a whole-the sum, the average production times number of individual agents-the economy must thus grow. Simply reducing the population will therefore not work, unless the average consumption of the rest will over-compensate for the loss of consumption units. It would then anyway mean an increased energy consumption and accelerated destruction of our planet, the things we want to avoid. This answers the third question. No, in a free market it is not possible to solve the problem by lowering the population.

Solution 1, switching to renewable energies seems, at first sight, a step in the good direction. We can have less of "bad" energy (of fossil fuels) and more of "good" energy. First of all, don't forget that the labeling of this fossil energy to be bad is not because they are bad-a hypothesis that is easily rejected (Stallinga, 2018; Stallinga \& Khmelinskii, 2018)—but only used as a control idea, as made clear by the one-world-governance agenda (see the book First Global Revolution mentioned in the beginning). The idea is not to reduce fossil fuel energy, but to control society to consume less energy, full stop. It is easily understood, because using renewable energies instead of fossil fuels does not change the concept of the game being an exponentially-growing system. It opens a new source of energy, but it will not be one that replaces fossil fuels-and even if it does-it merely adds to energy consumption. Why? Because it is possible in a free market and it is lucrative (in terms of energy and thus money). Moreover, it is highly unlikely that renewable energies are profitable (in energy terms); the fact that they continue to need subsidy proves that they are not efficient in a free market. See the reasoning above. Renewable energies cost more energy than they deliver in their lifetimes, except hydroelectrics. That is the reason that they need subsidies. If politicians want to save the planet, they should stop interfering into the economy, which only makes the economy less efficient, i.e., more polluting for the same amount of wealth produced (so, with political interference we either get less wealth for the same pollution or more pollution for the same wealth). We can also see this in the world emission figures of the last decades (Figure 5). While most countries are already in an energy-transition program, global carbon dioxide emissions continue to increase. "Whilst data from 2014 to 2017 suggested global annual emissions of $\mathrm{CO}_{2}$ had approximately stabilized, data from the Global Carbon Project reported a further annual increase of $2.7 \%$, and $0.6 \%$ in 2018 and 2019, respectively" (Data, 2020). The brunt being taken by China, which produces most renewable energy equipment such as photovoltaics and is suffering from huge smog problems. Manufacturing has been transferred from Europe and America to developing countries. The former writing nice 


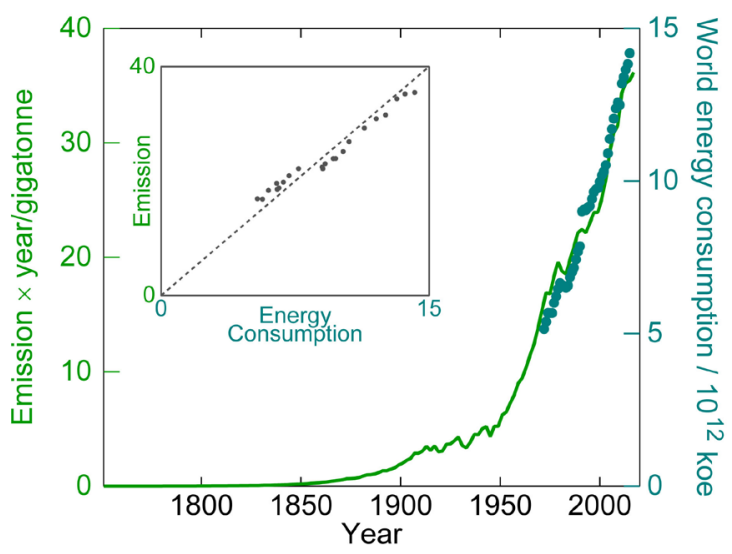

Figure 5. $\mathrm{CO}_{2}$ emissions worldwide continue to grow even in the presence of several first-world countries being in energy transitions. Data source: Our World In Data (Data, 2020). Energy consumption is consumption per capita multiplied by size of population. Data sources: The World Bank (The World Bank, 2020) and worldometer (worldometer, 2020). The carbon emission is proportional to the energy consumption (inset), indicating not much change of energy type has taken place, yet.

reports on how clean they are, the latter using the opportunity to develop themselves.

The figure also shows that the carbon emission is proportional to the energy consumption (inset), indicating not much change of energy type has taken place, yet. We can expect some transition to lower-carbon energy carriers, away from pure carbon (coal) to such as oil, gas, and nuclear. This has not significantly taken place, yet.

Interestingly, when we plot the same data of Figure 5 in a logarithmic scale (see Figure 6), we can recognize the 5\% growth figure of Piketty in the emissions. The figure shows various regimes: Before ca. 1800 the economic growth is mainly through harnessing natural power and while economy grew (at 5\%), emissions didn't grow fast. After 1800 fossil sources-mainly coal-started becoming important and economy and energy consumption and emissions grew at a 5\% rate (unfettered capitalism). The two world wars (1915-1945, an epoch that can be labeled "strangulating fascism" with governments heavily interfering in economy, even in the "free" world) reduced the growth rate in emissions significantly. Capital was not used to produce more capital, but only bellicose tools, mainly for the (mutual) destruction of the capital of the opponents. Growth of emissions was much slower.

After peace returned, it was business (and economy) as usual. After 1971, when the gold standard was abolished, the growth rate dropped again. (Interfering in economy by the banking scheme-fiat money-had a detrimental effect on the economy similar to the effects of war in the strangulating-fascism epoch). Possibly also due to a transition to low-carbon fuels such as oil, gas, or even nuclear, but from Figure 5 we see that emissions and consumption keep their proportionality. The (government-induced) oil crisis may also have had an effect, but that was too short-lived to have a major impact. 


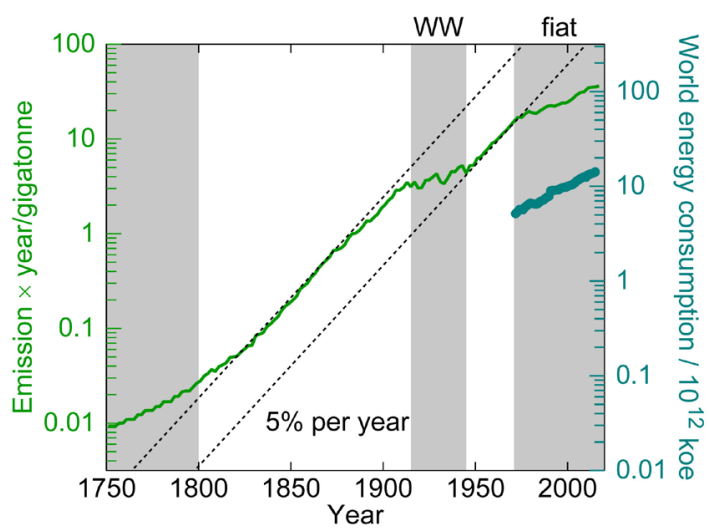

Figure 6. $\mathrm{CO}_{2}$ emissions on a logarithmic scale. Data source: Our World In Data (Data, 2020). Energy consumption per capita multiplied by population every year (Source: worldometer (worldometer, 2020)). We can recognize various phases in the world economy.

One might think there is a conspiracy of oil companies to protect their business. However, nothing can be further from the truth. Oil companies, not being philanthropists, couldn't care less where their profit comes from. They simply must make profit (in a free market), or exit the market through bankruptcy, leaving the market in the hands of profit-making less-scrupulous companies. A tendency amongst the greatest oil companies is to switch from fossil fuels to the art of raking in state subsidies, an endeavor that is much less risky than oil prospection, which happens mostly in countries with dubious and unreliable regimes that can only be persuaded to help by sending in the troops. (An example is Iran that confiscated the British Petroleum assets in 1954 and even refuses to give them back upon threats of war and the West, especially the British and their allies the United States, calling them all kinds of names). Royal Dutch Shell has recently fully withdrawn from a gas prospection consortium with the Dutch state (NAM) in The Netherlands (leaving the state to pay for the damages it caused to the houses built on the earthquake-ridden settling ground) and more and more dedicates itself to building windmill parks (especially at sea). If windmills are energetically favorable, they need no subsidies, because with them you can get rich while sleeping. Yet, with subsidies they become windhandel, an adequate Dutch word literally translated to "wind trade" but meaning a purely speculative trade with an eye on profit-only for which no reasonable grounds exist whatsoever. To show this, the Netherlands is a country defined by the fight against water (inundation) because it is mostly below sea level. An age-old application for windmills is water pumping, typically an Archimedes screw connected to a windmill axis. It is what the Dutch used to reclaim the land from the sea. In the 21st century, however, no windmill whatsoever is used for draining the land, in spite of it being the most efficient form of applying wind power. More so, since by the nature of the application also no extra infrastructures like storage are needed; Draining and water infiltrations are very slow processes and variations in wind intensity are therefore irrelevant. Windmills can moreover be 
built right there where the water is to be pumped away. In the 21st century, believe it or not, windmills are built at sea, the generated electric power transported to land, where it has to be stored or buffered, and then electric power is supplied to electrical Archimedes' screws. This flagrant loss of efficiency is made possible by governments that are not Smithian-style liberating the market but start instead interfering in it and thus lower the wealth (useful energy). In such cases of inefficiency, where not the consumers decide what is produced, no energy consumption is lowered, only energy is wasted and not used for consumption; it directly goes into entropy, see Figure 7. Humans, through which no longer flows the energy, simply die. An important note here is that for the owners of the means of production $M$-the capital-it does not matter at all if the production is wasted. What is important is that production takes place since such production enriches the producers, i.e. the owners of the means of production, through an associated production of capital $K$. That is why, for instance, the government in Brussels, by name of vice president Frans Timmermans, ordered by the owners of the means of production (The European Round Table of Industrialists, ERT, that together with other industrial lobbyists writes $75 \%$ of the European laws (Moser \& Lietaert, 2012)), has now set aside one trillion $\left(10^{12}\right.$ or $1,000,000,000,000)$ euros for addressing climate change in the next multi-year economic plan. Involving windmills, the character of Don Quixote springs to mind.

In extremis. It is actually possible in a capitalist totally-free society (without any democratic feedbacks and limiting factors such as elections) that the means of production will only maintain and produce means of production and will hire and pay robots (i.e., other means of production) to do the work, fully bypassing humans, only producing $K$ and no $C$ or $W$. Imagine you are the owner of a factory and for half the price you can hire robots to do the work, wouldn't you do it? (Example are the automated tellers instead of human cashiers at large supermarkets). And if your factory sells to other factories and factory robots instead of humans, would you really care? Is it not your goal as an entrepreneur to make profit? The fact is that all economy is made up of entrepreneurs that think and act like you. Actually, even worse, the goal of the capital is to remove you as entrepreneur as well, because you are too expensive; you'd better be replaced by

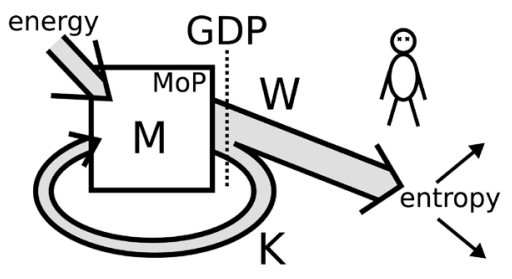

Figure 7. If energy $W$ is wasted (for example when making windmills), energy is directly converted into entropy without any benefit for humans (i.e. consumption). The owners of the means of production-the capital-do not care; it is for the ones who make the decisions in the production process only important that production takes place (and profit $K$ is assured), not what the type of production is, $W$ (this figure) or $C$ (Figure 2). 
a robot or an $\mathrm{AI}$ in general, that can do your work much more efficiently, also including your management activities. There is no limit to the game, when you understand it is just an energy game. That is why, for optimization of the economy, the democratic process (that gives an unfair advantage to inefficient human units in the economy) has to be abolished. Capital should fully rule in politics to have a faster production of entropy. To enable this, capital invests in lobbying the decision makers (see for instance the ERT mentioned before), which amounts to bypassing the democratic process. When human consumers have a say in things, they'll demand production of consumer goods $C$ and a natural law is that $5 \%$ is left for capital growth $K$. When humans have no say in things, $5 \%$ goes to capital $K$ and $95 \%$ goes to waste $W$.

But let's continue. It gets worse. A "Cap-and-Trade" market, an imagined solution to the problem, with carbon-emission rights being traded on an assets market, is such an aforementioned waste-producing scheme. It will not ever reduce carbon-dioxide emissions. Putting tax on energy will not reduce energy consumption. It will, at best, have no effect whatsoever, except for control of society. That is because, at best, not even interference in the market takes place as described above. It is, at best, a waste of effort.

To show this, imagine we still have a gold (energy) standard as money in the economy. And imagine we want to reduce the energy consumption (not only fossil fuels). That means, because we want to reduce the economy in energetic terms, we must reduce the economy also in monetary terms, since with gold the two are linked (one troy ounce of gold has a market-exchange value of $x$ joules of energy, the energy it takes to produce it). That means that we must induce an economical crisis.

Think of this. If the economy is gold-money-based, it is a zero-sum game by definition (since nearly no more gold is added to the system). That means that the state must not make a monetary profit, or the rest (citizens/consumers and capital) will make a monetary loss and that is unsustainable because in such an economical environment nobody will invest and produce and poverty will strike; a Marxian crisis of overproduction. That means that government must make a loss, and every euro income by tax, to reduce consumption (joules), must be accompanied by an equal or greater incentive to consumption (subsidies) or direct government consumption. The net effect will be zero, at best. No reduction of energy consumption can be accomplished by fiscal policies.

One may think that the subsidies/tax system including Cap-and-Trade will make the economy and society switch away from fossil fuels and go into renewable energy sources. But that would be not understanding the energetic game. These renewable energy products ("capital") are produced from energy too (see Figure 2) and that means that the (free) market price will be based on the price of fossil fuels, for the exact reason how the market works. Supply and demand establishing prices. That means that if fossil fuels are taxed to increase their price, this price will percolate to the price of all other products, including renewable energy capital and renewable energy itself. What results is merely an 
increase of price of energy. But that cannot be, because money = energy and energy $=$ money, so it will have no effect whatsoever. We can see this from the fact that already for decades renewable energies were promising to be profitable "just around the corner, beyond the horizon. A couple of years more and they'll be self-sustaining". Who understands the energy-economy game knows this will never happen, barring some technological breakthrough that would be a game-changer, which even the author is working on fervently (Timmerman et al., 2008).

One curious side effect of the Cap-and-Trade system, when placed in a modern society where assets can be used as a basis for (fractional-reserve) bookkeeping schemes, carbon-emission rights will be used in a fractional-reserve carbon-rights system and actually multiplied. Every ton of emission rights will be twenty times multiplied, so there will exist twenty tons of emission rights. At least on the balance sheets. If it has any relation to reality is of no concern to the bookkeeper.

On the other hand, in an economy where money and energy (gold) are decoupled, it merely results in a rising of prices of all products, i.e., inflation, without the economy changing a iota. It is therefore not possible to tax "dirty" energy and subsidize "clean" energy. At best, it has no effect. At worst, it is an interference in free-market economy and merely benefits those companies that make these products and sell this type of energy that were represented in government. As an example may serve $\mathrm{Al}$ Gore, the first renewable-energy billionaire. Smith turns around in his grave. All such measures, as Smith argued, decrease the efficiency in economy and lower the wealth of nations. They simply control the people by saying their entire life is a sin from birth and it is better for them if they live in sobriety. That can be done; consumption can be taken away from people, but only at the cost of an increase of waste $W$ substituting consumption $C$, since entropy must increase and the rate of production of entropy must also increase, i.e., it is an exponential-energy system.

Cap-and-Trade is good for a subset of companies in the world-those that make renewable-energy products-and it is good for control of the people, because it enables, through taxing and subsidies, to plan what products are consumed by whom and when. Because in a free market the renewable energies will not replace fossil fuels, but simply add to them (why? because they can!) the energy consumption will continue to increase forever. Because also renewable energies are limited (not in joule, but in watt), even if fossil sources are fully replaced by renewable sources, there will sooner or later be a limit to growth. It is simply kicking the can down the road and ignoring the unavoidable.

This answers the first question. Remains to answer the second question, is it possible to have a constant-energy economy in a free market with some kind of banking scheme? Looking at Equations (1) and (2) and Figure 2 and Figure 7, it means $\beta=0$ (all production is consumption $C$ or waste $W$ ), $K=0$ (no profit), $M(t)=M_{0}$, and $C(t)=\alpha M_{0}$. If the objective of companies is to make monetary profit and not energetic profit, and the two are unlinked by the finan- 
cial fiat-money scheme, can capitalist agents in society continue to be incentivated to produce the consumption goods for society? For that we have to go to psychology. Let's ask it like this: Would you be interested in a scheme to, let's say, sell your house for $X$ euros, use these euros as an investment (buy raw materials, hire personnel, etc.), make with this another $X$ euros profit, and then at the end with these $2 X$ euros being able to ... buy back your house, nothing more? Would you endeavor in such an enterprise? We presume not. Why do you think others would think differently? Yet, that is what it is, a constant steady-state economy; no new added wealth created. In a free market, all agents are acting in self interest and we can expect that in such an economy all agents think like you and nobody will do any business and we have a crisis of pessimism. That'll actually shrink the economy and then the crisis self-aggravates because a shrinking economy adds to pessimism. That seems to be the current state of the economy, the market understanding the uselessness of entrepreneurship when all you get, at best, is your joules back. If money itself is worthless and not an objective, there is thus no free market possible.

That answers the three questions with a "no". For the moment, at least, reality is that our consumption is forcedly increased. To not enter into a crisis, consumption is temporarily incentivated/forced so that production can continue (and continue to increase) by a forced transfer of wealth from people to capital, where unfettered capitalism creates wealth for the people and new capital. An example is the outlawing of diesel cars to make people buy electric cars as substitutes instead. For sure, these have an increased ecological footprint-including energetic footprint, more so since they substitute perfectly-working cars-but help to save the economy (help to increase entropy production necessary in a free market). Bad for the environment, but good for economy. To avoid the gloom of a steady-state economy and consequent economical collapse.

That means that the only solution is a transition to a communist planned-economy by destroying capitalism and replacing it with a pan-world government (mentioned in the introduction). This is clearly the plan (of some) as stated by, for instance, Christiana Figueres of the one-world-government aspirants, the United Nations (Durden, 2020),

This is the first time in the history of mankind that we are setting ourselves the task of intentionally, within a defined period of time, to change the economic development model that has been reigning for at least 150 years, since the Industrial Revolution.

However, we are very skeptical this will work, as history has shown-for instance by the Soviet Experiment-that it has never resulted before. On paper, mathematically, it works perfectly. People will produce-on paper-exactly what the system orders that they should produce and what is needed, so mathematically we cannot prove it will go wrong, though it goes against a natural force of increasing entropy (yet, compare with gravity: the force exists, but objects do not have to fall). The socialist politicians always have a very good heart, being mostly 
true adherents of the philosophy of Jean Jacques Rousseau, "[H]is stress on the importance of feeling and emotion made him an important influence on and anticipator of the romantic movement" (Stanford Encyclopedia of Philosophy, 2020). Yet, let us finish this section with the famous words, "The road to hell is paved with good intentions".

\section{Discussion}

It was first determined that the only way to express an economy is energy, the so-called energy theory of value (ETV). More precisely, the unit of economy is not GDP, but watt. Let's face it, it is the only unit that is reasonable and resides in the realm of physics. "Anything that exists has a unit S.I. (Systeme International d unités) and anything that has a unit S.I. exists" (Stallinga, 2020). A euro or dollar is not an S.I. unit, nor is it legally linked to it, by promising anything that has an S.I. unit. It is just a number. As such, like all numbers, euros or dollars simply belong to the world of mathematics, very beautiful, but not pertaining to reality.

Any product or service can be expressed in joule. Namely how much energy it cost to bring it to the market. It does not mean that it will be sold for that amount-after all the market is full of speculation-but it has that intrinsic value. The total economy is then the sum of all energetic intrinsic value produced in a year.

At any moment, coincidentally there can be a link between energy and money. With $X$ amount of money circulating the world, and the economy consisting of $Y$ watts, the ratio between the two is $X: Y$. That is the instantaneous market value of money. A euro "buys" a certain amount of products that represent a certain amount of energy. One can then even express the economy in a GDP. But if we want to see if the economy is doing better than the previous year one must not forget that the currency of last year has a different link value than this year and some adjustment has to be made. Had we done all calculation in joules, no such adjustment would have been necessary.

Since economy in a free (capitalist) world consists of doing investments and reaping their fruits, the economy must grow. After all, when people endeavor in an enterprise, they do so with the outlook on making profit. Investing 1 joule of capital, one hopes to get the 1 joule back, plus a profit. This is pure psychology as described by Kahneman (Kahneman, 2011). Think for yourself: If you have zero risk, how much profit do you want to make before you start investing? And what if there is a serious risk of losing your investment. How much profit do you want (or outlook thereon) before you invest? In all cases, one wants positive profit.

Taking a look at Figure 8, the top panel shows schematically the profit and probability distribution. The expectation value of profit is $\mu$ but it has a spread-"risk"-parameterized by $\sigma$. Even a loss can be made in the extreme case. The bottom panel shows the decision scheme of an average investor. If the risk is small (small spread in profit), even a tiny profit is enough to convince an investor. When the risk $\sigma$ increases, the investor wants to be compensated for 

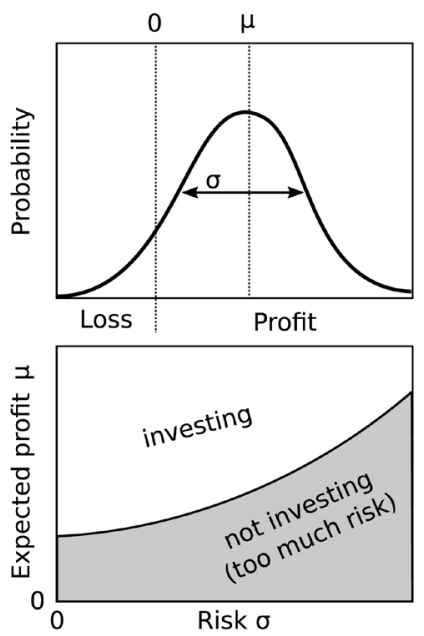

Figure 8. Decision graph of an investor. The enterprise is characterized by a certain expectation value of profit, $\mu$, and a risk ( $\sigma$; spread) of profit. When the risk is zero $\sigma=0$, the investor is happy with a small profit. When the risk $\sigma$ increases, the profit outlook has to increase before the investor starts entering in the enterprise. Never is a negative profit acceptable for investors.

assuming that risk, by an increased expectation value $\mu$ of profit. Never is a negative profit acceptable for investors!

That is why, in a free market, the market has to grow. Once the market stops growing, a crisis results. In such an economical environment, pessimism (lower outlook on profit) reduces further the will to invest and crises are thus self-aggravating. Since economy is energy, energy consumption must increase.

Disconnecting the link from energy to money (as we have done since 1971), hoping that investors are fooled by this trick, wont work on the long run. In an economic system where money can readily be made (printed out of thin air), but this money reduces fast in value, the outlook is once again negative and a crises results, probably in the face of hyperinflation. Investors want capital (joules) profit and not monetary profit. Money, in itself, is worthless. Money is just a number. Nothing more. The nothingness of money is more so visible in modern bank money, which is just a bit pattern; all bit patterns cost the same amount of energy, but do not have the same market value.

It is technically-on paper!- possible to centrally manage the economy as a steady-state system, without growth. However, this experiment has been performed and it failed miserably. The reason is that if compensation is no longer based on somebody's performance, this performance tends to go down rapidly. "From each according to his ability, to each according to his needs" (Marx, 1875) rapidly boils down to "Let them work, my abilities are none and my needs are grand!", as the Soviet Experiment has shown.

In conclusion, we have shown here, based on three postulates 1: economy is energy, 2: in a free market all parties are happy in trades, 3: physics laws demand that economy (entropy) must increase), that an economy with a currency that is based on energy (for instance gold) will stagnate. When the currency is no long- 
er based on energy (or anything else), money is worthless, and the incentive of economy (production, trade, etc.) disappears and economy will stagnate too when no energetic gain can be obtained. Even trying to force people into consumption and saving the economy is a temporary measure. The only solution is taking away the freedom of the market-accompanied by taking away other liberties of citizens as well-and enter a centralized planned economy, where humans are mere assets on the balance sheet of society. The climate change scare is a perfect tool in achieving this objective. It unites people against a common threat and they are then willing to hand over all their wealth and liberties so that they can be managed more easily by the elite. Yet, we foresee social problems and mass upheavals when soviet-style poverty inevitably strikes the population. We see no reason why it would be different this time around.

As seen, this work does not come up with a ready-made solution to the problems our society is facing in terms of economic policy. This work does not try to give recommendations since it is a work of research and not a work on politics. If giving any recommendations, it would be that everybody in the world should have freedom to decide for themselves, since it motivates people the most (yet this is not directly proven here, apart from that it seems biologically more viable for individuals to optimize their individual success rate). To make use of the freedom maybe this text will help them make a decision by being better informed about the consequences of their decisions. Freedom of choice, however, is by definition conflicting with a centralization of the economy and government.

\section{Conflicts of Interest}

The author declares no conflicts of interest regarding the publication of this paper.

\section{References}

Agency, European Environment (2020). Correlation of Energy Consumption and GDP Per Person.

https://www.eea.europa.eu/data-and-maps/figures/correlation-of-per-capita-energy

Akten, M. (2020). The Answer to the Fermi Paradox, Why We Are the Chosen Ones, and the Meaning of Life.

https://medium.com/@memoakten/the-answer-to-the-fermi-paradox-why-we-are-thechosen-onesand-the-meaning-of-life-b6c40391d129

Ångström, K. (1900). Ueber die Bedeutung des Wasserdampfes und der Kohlensäure bei der Absorption der Erdatmosphäre. Annalen der Physik, 308, 720-732. https://doi.org/10.1002/andp.19003081208

Ayres, R. U. (2001). Resources, Scarcity, Growth and the Environment.

Berndt, E. R. (1981). From Technocracy to Net Energy Analysis: Engineers, Economists and Recurring Energy Theories of Value. Studies in Energy and the American Economy. ASIN B00070SQAE. Energy Laboratory, Sloan School of Management, Massachusetts Institute of Technology.

Bloomberg (2019). Inside the Tokyo Whale's Unstoppable Rise. 
https://vigilantcitizen.com/latestnews/the-25-rules-of-disinformation/

Callendar, G. S. (1938). The Artificial Production of Carbon Dioxide and Its Influence on Temperature. Quarterly Journal of the Royal Meteorological Society, 64, 223-240. https://rmets.onlinelibrary.wiley.com/doi/abs/10.1002/qj.49706427503 https://doi.org/10.1002/qj.49706427503

Citizen, The Vigilant (2019). The 25 Rules of Disinformation. https://www.bloomberg.com/news/articles/2016-08-14/the-tokyo-whale-s-unstoppable -rise-to-shareholder-no-1-in-japan

CNBC (2016). Deutsche Bank: Why It Has Investors So Concerned. https://www.cnbc.com/2016/07/15/deutsche-bank-a-ticking-time-bomb.html

Daly, H. E. (1986). Thermodynamic and Economic Concepts as Related to Resource-Use Policies: Comment. Land Economics, 62, 319-322. http://www.jstor.org/stable/3146396 https://doi.org/10.2307/3146396

Data, Our World in (2020). $\mathrm{CO}_{2}$ and Greenhouse Gas Emissions. https://ourworldindata.org/co2-andother-greenhouse-gas-emissions\#global-warming-t o-date

Davig, T. et al. (2015). Bank Consolidation and Merger Activity Following the Crisis. Economic Review, No. 1, 31-49.

Davig, T. et al. (2017). Community Bank Mergers Since the Financial Crisis: How Acquired Community Banks Compared with Their Peers. FDIC Quarterly, 11, 41-52.

Durden, T. (2020). U.N. Official Admits Global Warming Agenda Is Really about Destroying Capitalism.

https://www.zerohedge.com/news/2017-02-03/un-official-admits-global-warming-agen da-reallyabout-destroying-capitalism

Ehrlich, P. R. (1968). The Population Bomb. New York: Sierra Club/Ballantine Books.

England, J. L. (2013). Statistical Physics of Self-Replication. Chemical Physics, 139, Article ID: 121923 . https://doi.org/10.1063/1.4818538

Express (2020). Germany Economy Crisis: How Recession Risk Could Spread across Europe in Post-Brexit Blow.

https://www.express.co.uk/news/world/1166465/germany-economy-crisis-recession-an gela-merkelcrisis-europe-economy

Farlex, The Free Dictionary by (2020). Deed. https://legal-dictionary.thefreedictionary.com/deed

Garrett, T. J. (2011). Are There Basic Physical Constraints on Future Anthropogenic Emissions of Carbon Dioxide? Climatic Change, 104, 437-455.

https://doi.org/10.1007/s10584-009-9717-9

Geological Society of London Blog (2019). Geology vs. Climate Change. https://blog.geolsoc.org.uk/2019/02/04/geology-vs-climate-change/ https://doi.org/10.4172/2573-458X.1000169

Georgescu-Roegen, N. (1971). The Entropy Law and the Economic Process. Cambridge, MA: Harvard University Press. https://doi.org/10.4159/harvard.9780674281653

Gold, S. (2020). We Don't Have a Wage Problem; We Have a Money Problem. https://schiffgold.com/keygold-news/we-dont-have-a-wage-problem-we-have-a-money -problem/

Hardin, G. (1968). The Tragedy of the Commons. Science, 162, 1243-1248.

https://doi.org/10.1126/science.162.3859.1243 
Insider, Business (2019). Small US Banks Are Merging to Pursue Greater Scale and Cost Efficiencies.

https://www.businessinsider.com/small-us-banks-join-forces-for-growth-2019-8

Jankovici, J. M. (2005). How Much of a Slave Master Am I?

https://jancovici.com/en/energy-transition/energy-and-us/how-much-of-a-slave-maste r-am-i/

Judson, D. H. (1989). The Convergengce of Neo-Ricardian and Embodied Energy Theories of Value and Price. Ecological Economics, 1, 261-281. https://doi.org/10.1016/0921-8009(89)90009-8

Juggler, Unit (2020). Convert kg of Oil Equivalent to Megajoules. https://www.unitjuggler.com/convertenergy-from-koe-to-MJ.html

Kahneman, D. (2011). Thinking, Fast and Slow. Farrar, Straus / Giroux.

Kardashev, N. S. (1964). Transmission of Information by Extraterrestrial Civilizations. Soviet Astronomy, 8, 217-221.

King, A., \& Bertrand, S. (1991). The First Global Revolution: A Report by The Council of The Club of Rome. New York: Pantheon Books.

Marois, T. (2017). How Public Banks Can Help Finance a Green and Just Energy Transformation. Public Alternatives Issue Brief.

Marx, K. (1875). Critique of the Gotha Program (German: Kritik des Gothaer Programms).

Meadows, D. H. et al. (1972). Limits to Growth. Potomac Associates.

Moser, F., \& Lietaert, M. (2012). The Brussels Business. Movie.

Piketty, T. (2013). Capital in the Twenty-First Century. Editions du Seuil Harvard University Press. https://doi.org/10.4159/9780674369542

Probe (2019).

https://probe.org/utilitarianism-the-greatest-good-for-the-greatest-number/

Rancourt, D. G. (2019). Geo-Economics and Geo-Politics Drive Successive Eras of Predatory Globalization and Social Engineering: Historical Emergence of Climate Change, Gender Equity, and Anti-Racism as State Doctrines. Ontario Civil Liberties Association Report.

Scott, H. (1933). Technology Smashes the Price System. Harpers Magazine, 166, 129-142.

Smith, A. (1776). An Inquiry into the Nature and Causes of the Wealth of Nations. https://doi.org/10.1093/oseo/instance.00043218

Stallinga, P. (2017). The Magic Number Seven for Companies in Mature Markets. Journal of Economics, Management and Trade, 19, 1-10. https://doi.org/10.9734/JEMT/2017/36828

Stallinga, P. (2018). Signal Analysis of the Climate: Correlation, Delay and Feedback. Journal of Data Analysis and Information Processing, 6, 30-45. https://doi.org/10.4236/jdaip.2018.62003

Stallinga, P. (2020) On the Existence of Things. Work in Progress.

Stallinga, P., \& Khmelinskii, I. (2014). The Scientific Method in Contemporary (Climate) Research. Energy \& Environment, 25, 137. https://doi.org/10.1260/0958-305X.25.1.137

Stallinga, P., \& Khmelinskii, I. (2018). Analysis of Temporal Signals of Climate. Natural Science, 10, 393-403. https://doi.org/10.4236/ns.2018.1010037

Stanford Encyclopedia of Philosophy (2020). Jean Jacques Rousseau. https://plato.stanford.edu/entries/rousseau/

The World Bank (2020). Data Bank. https://databank.worldbank.org 
Timmerman, D. et al. (2008). Space-Separated Quantum Cutting with Si Nanocrystals for Photovoltaic Applications. Nature Photonics, 2, 105.

https://doi.org/10.1038/nphoton.2007.279

Upcounsel (2019). Contract without Consideration Is Void. https://www.upcounsel.com/contract-withoutconsideration-is-void

Wehrmann, B. (2019). Central Banks Must Stay Neutral on Climate Policy, German Bundesbank Says.

https://www.cleanenergywire.org/news/central-banks-must-stay-neutralclimate-policygerman-bundesbank-says

Wikipedia (2020a). Efficient Market Hypothesis.

https://en.wikipedia.org/wiki/Efficient-market hypothesis

Wikipedia (2020b). Labor Theory of Value.

https://en.wikipedia.org/wiki/Labor theory of value

Wikipedia. (2020c). Public Bank. https://en.wikipedia.org/wiki/Public bank

Worldometer (2020). World Population by Year.

https://www.worldometers.info/world-population/worldpopulation-by-year/ 